\title{
Correction of the Structure of a New
}

\section{Sesquiterpene from Cistus creticus ssp.}

\section{creticus}

Konstantinos Hatzellis, ${ }^{\dagger}$ Georgia Pagona, ${ }^{\dagger}$ Apostolos Spyros, ${ }^{\dagger}$ Costas Demetzos ${ }^{*, \neq}$ and

Haralambos E. Katerinopoulos ${ }^{*,}$

Department of Chemistry, University of Crete, Heraklion 71409, Crete, Greece, and

School of Pharmacy, Department of Pharmaceutical Technology, Panepistimiopolis Zografou 15771, University of Athens, Athens, Greece.

* To whom correspondence should be addressed. Tel.: +30 2810393 626. Fax: +30 2810393 601. E-mail: To whom correspondence should be addressed. Tel.: +30 2810 393 626. Fax: +30 2810393 601. E-mail: kater@chemistry.uoc.gr, and Fax:+301210-7274596. E-mail:demetzos@pharm.uoa.gr.

${ }^{\dagger}$ University of Crete.

University of Athens. 
Table of contents:

${ }^{13} \mathrm{C}$ NMR spectrum of compound $9 \quad$ S3

$\begin{array}{ll}{ }^{1} \mathrm{H} \text { NMR spectrum of compound } \mathbf{9} & \mathrm{S} 4\end{array}$

${ }^{1} \mathrm{H}$ NMR spectrum of compound 10b. $\quad$ S5

${ }^{13} \mathrm{C}$ NMR spectrum of compound 10b $\quad$ S6

$\begin{array}{ll}{ }^{1} \mathrm{H} \text { NMR spectrum ofcompound } \mathbf{1 1} & \text { S7 }\end{array}$

$\begin{array}{ll}{ }^{13} \mathrm{C} \text { NMR spectrum of compound } \mathbf{1 1} & \text { S8 }\end{array}$

${ }^{1} \mathrm{H}$ NMR spectrum of compound $\mathbf{1 2}$.

$\begin{array}{lr}{ }^{13} \mathrm{C} \text { NMR spectrum of compound 12. } & \mathrm{S} 10\end{array}$

${ }^{1}$ H NMR spectrum of compound 2. $\quad$ S11

${ }^{13} \mathrm{C}$ NMR and DEPT $\left(135^{\circ}\right)$ spectra of compound $2 \quad \mathrm{~S} 12$

HMQC spectrum of compound 2. $\quad \mathrm{S} 13$

NOESY spectrum of cis decalin system 9. $\quad$ S14

Mass spectra of isomeric compounds 9 and 12. $\quad \mathrm{S} 15$

Mass spectrum of compound 2. $\quad$ S16

COSY Spectum of Natural Product 3. $\quad$ S17

HMQC Spectrum of Natural Product $3 . \quad$ S18

HMBC (long range C-H) Spectrum of Natural Product $3 . \quad$ S19

${ }^{1}$ H NMR Spectrum of Natural Product $3 . \quad$ S20

$\begin{array}{ll}{ }^{13} \mathrm{C} \text { NMR Spectrum of Natural Product 3. } & \text { S21 }\end{array}$

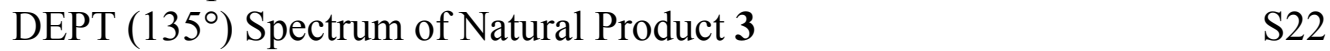

Mass Spectrum of Natural Product 3. $\quad$ S22 


\section{${ }^{13} \mathrm{C}$ NMR spectrum of compound 9}

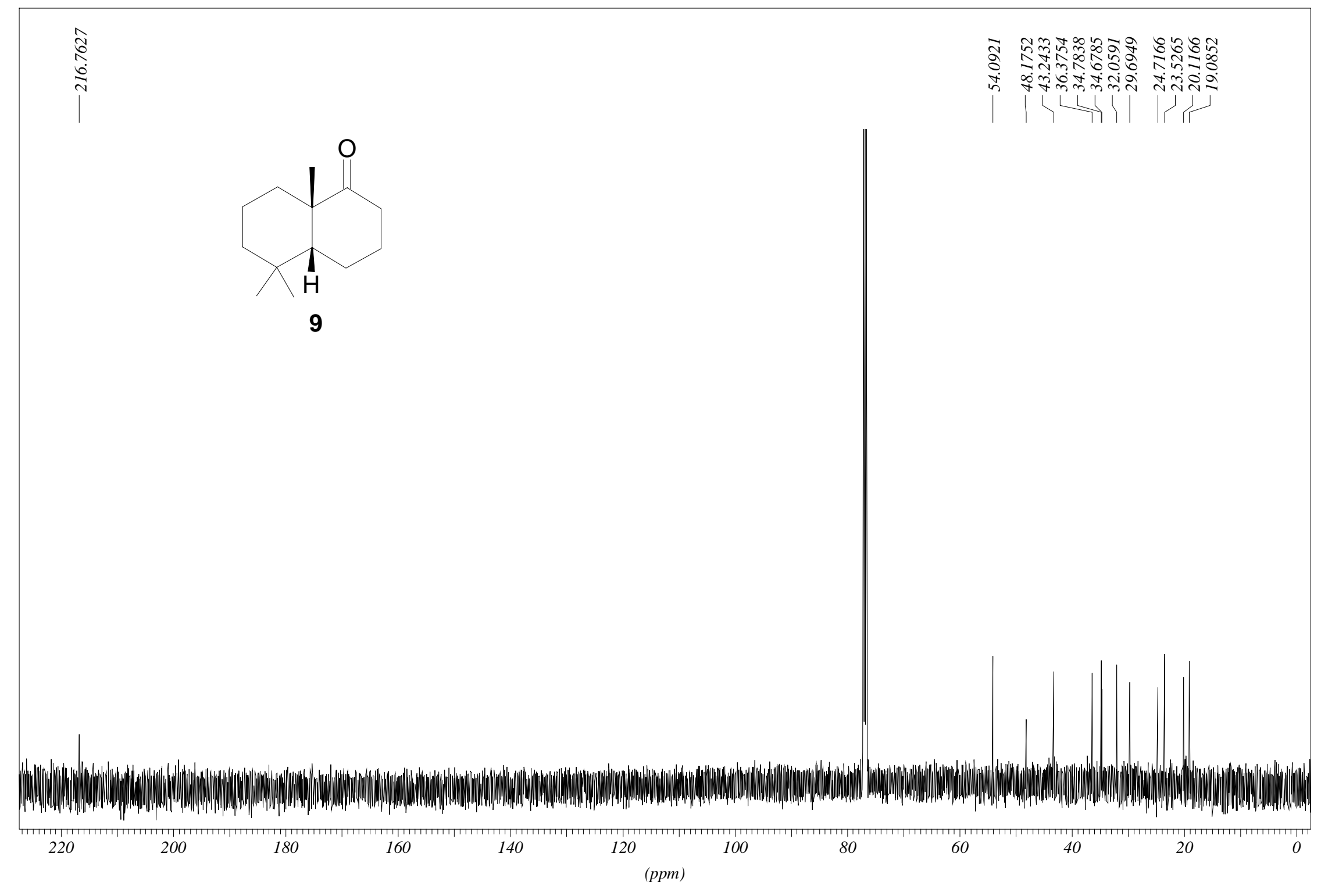




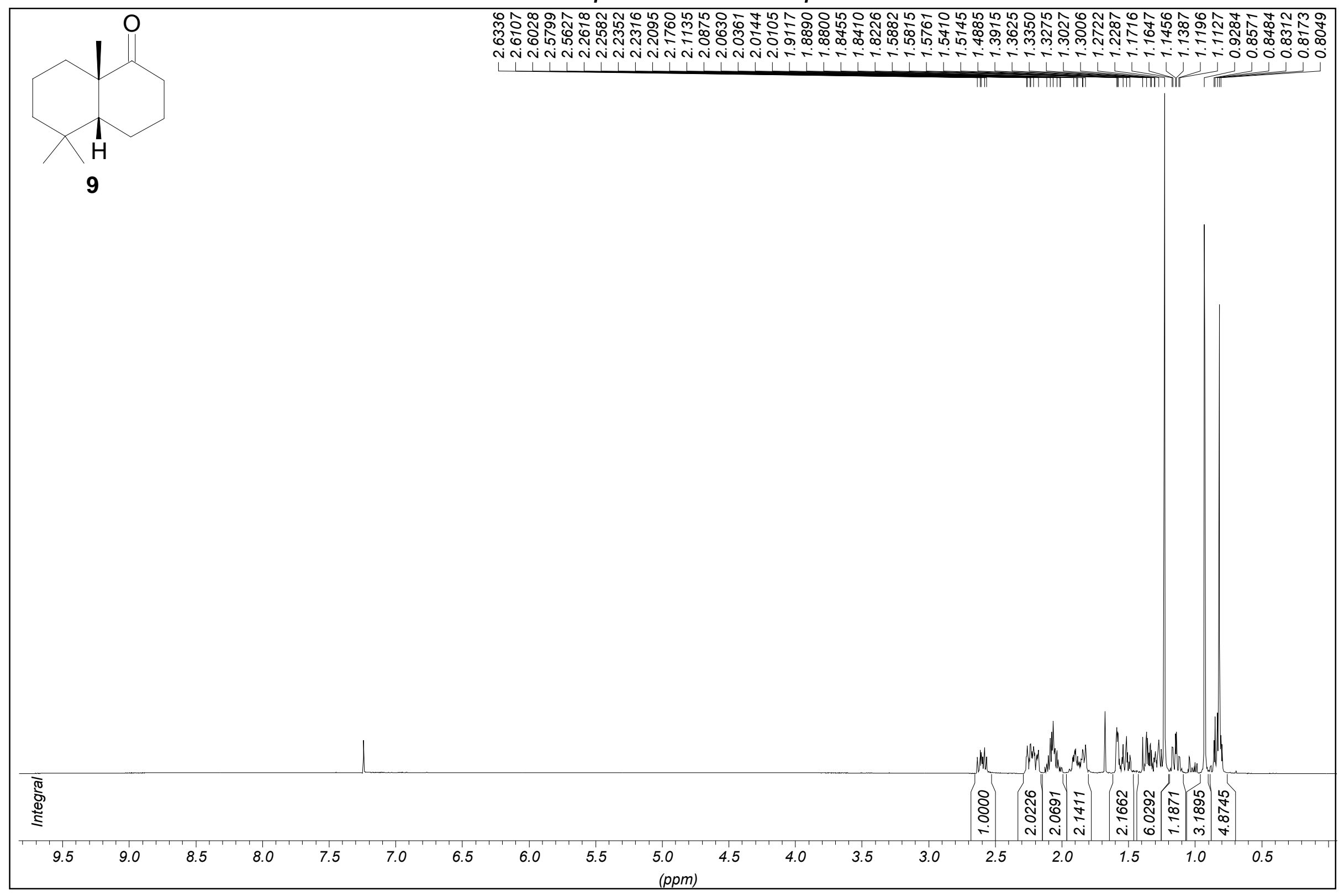




\section{${ }^{1} \mathrm{H}$ NMR spectrum of compound $10 \mathrm{~b}$}

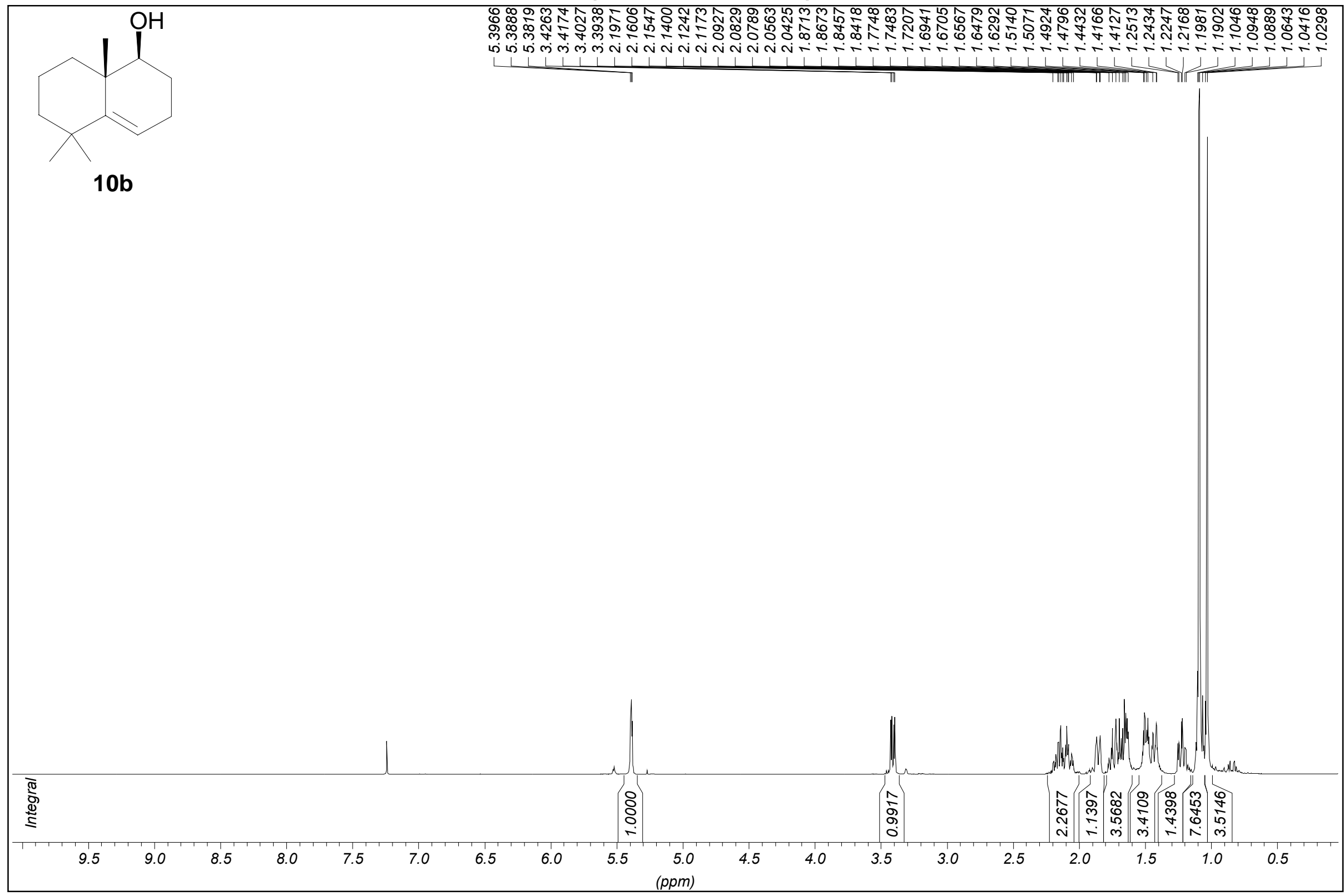


${ }^{13} \mathrm{C}$ NMR spectrum of compound $10 \mathrm{~b}$

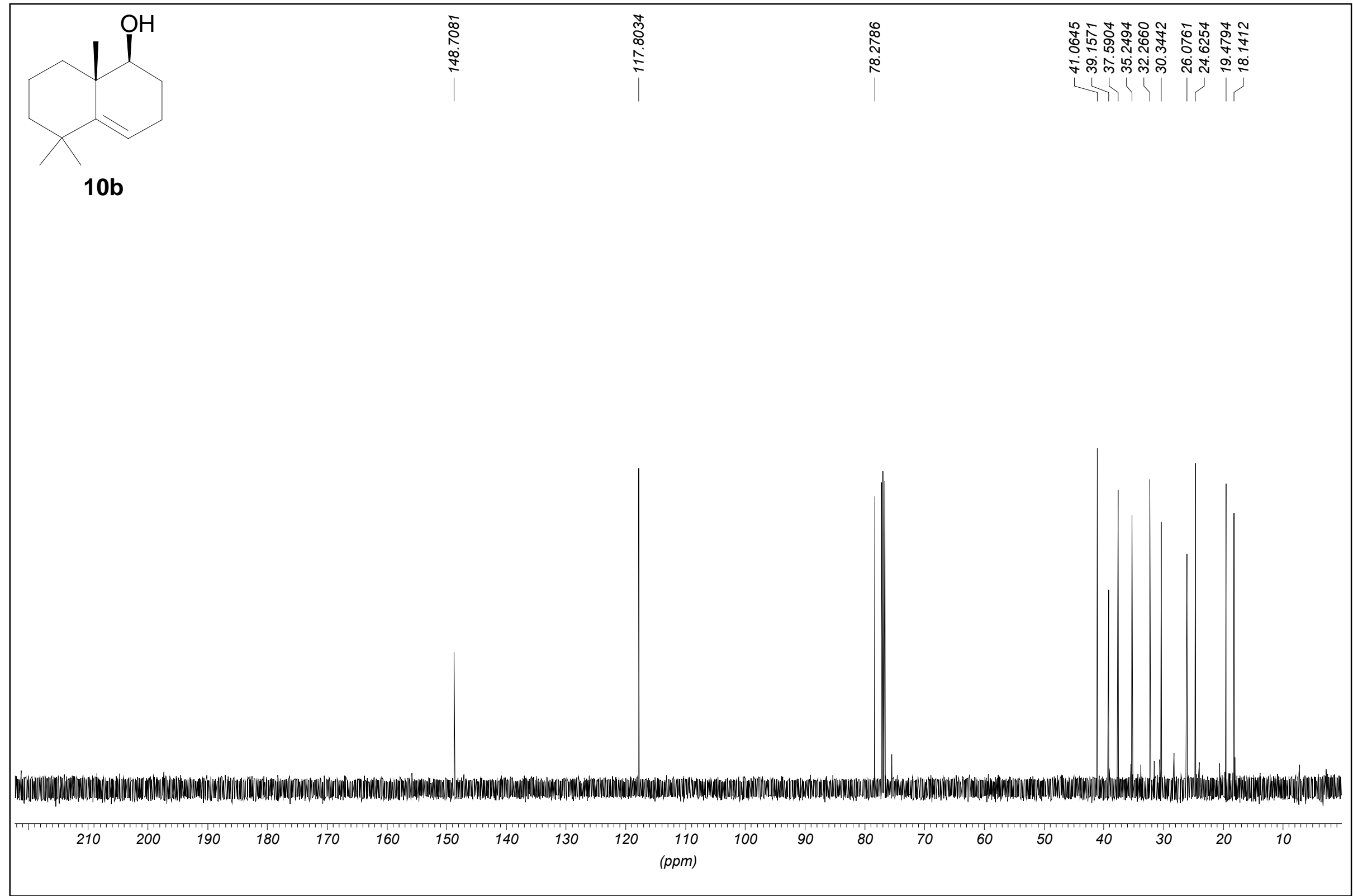




\section{${ }^{1} \mathrm{H}$ NMR spectrum ofcompound 11}

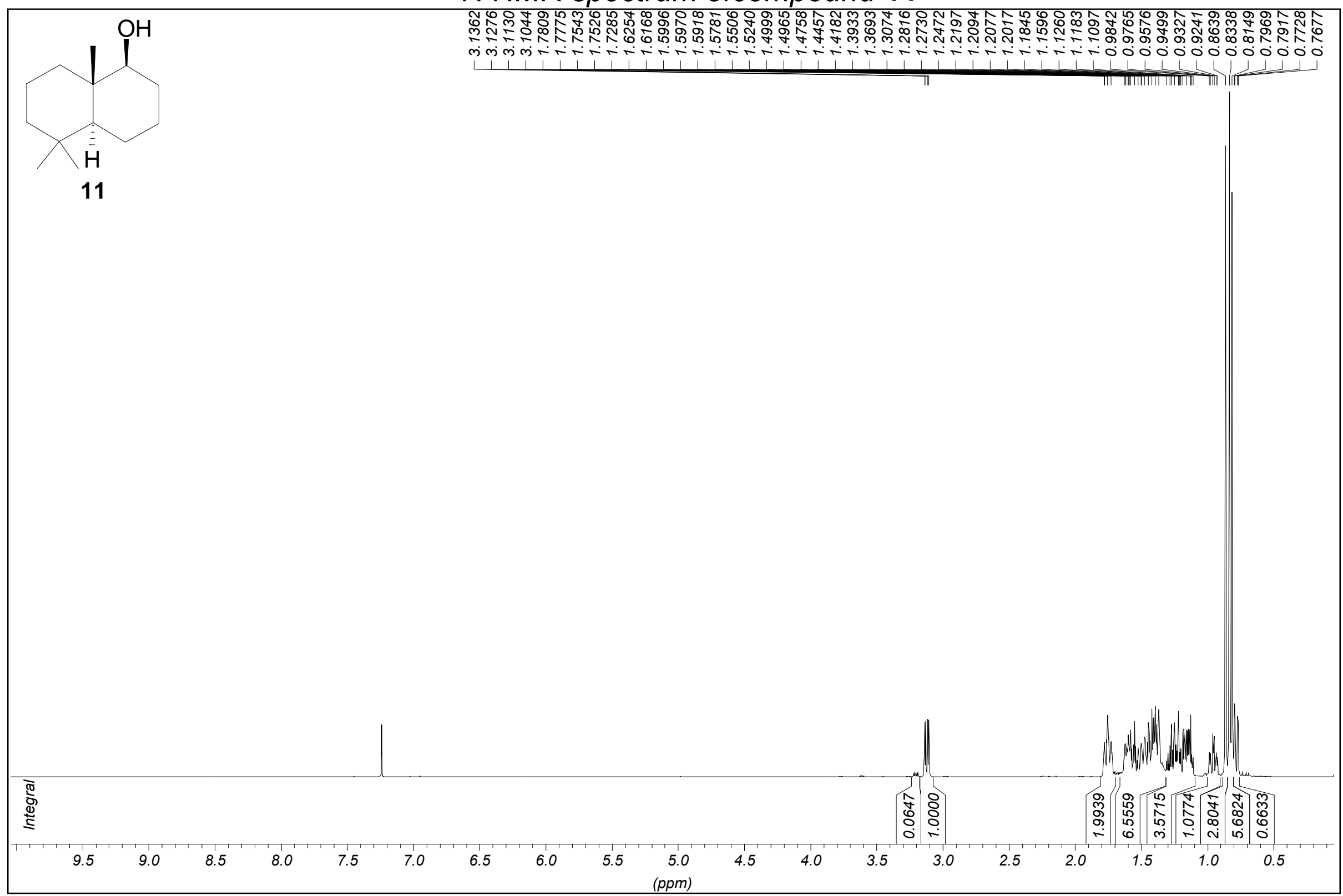


${ }^{13} \mathrm{C}$ NMR spectrum of compound 11

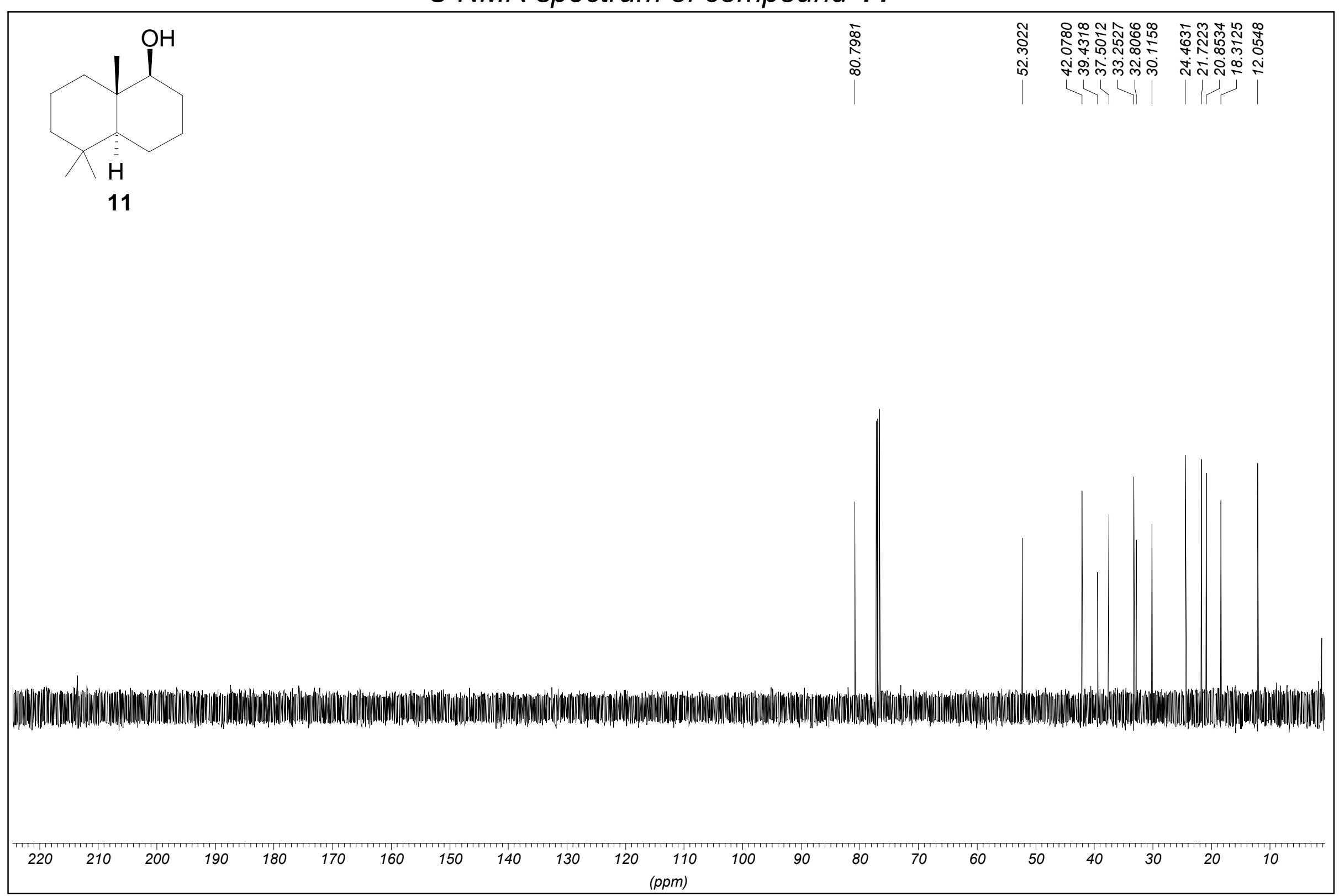


${ }^{1} \mathrm{H}$ NMR spectrum of compound 12

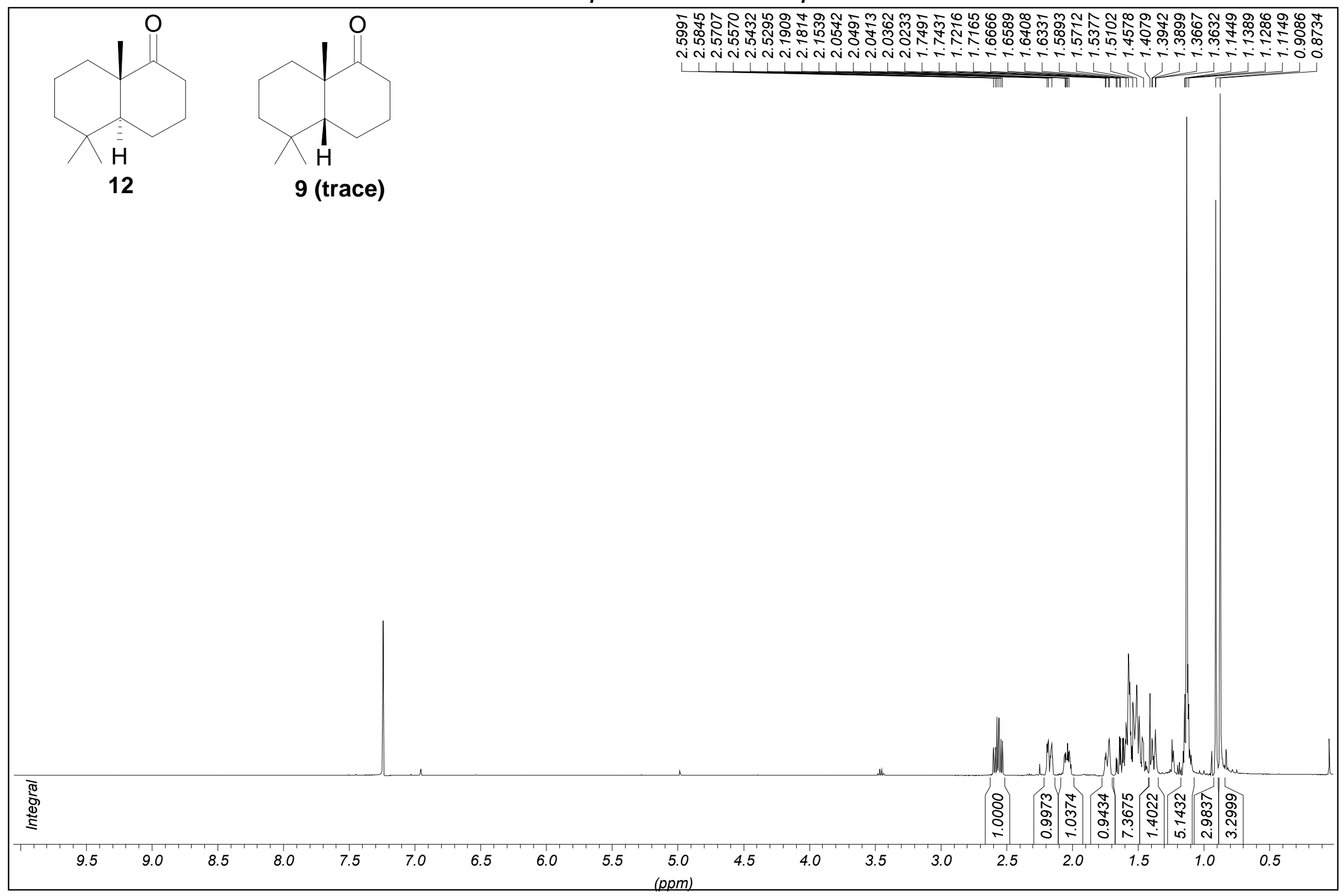


${ }^{13} \mathrm{C}$ NMR spectrum of compound 12

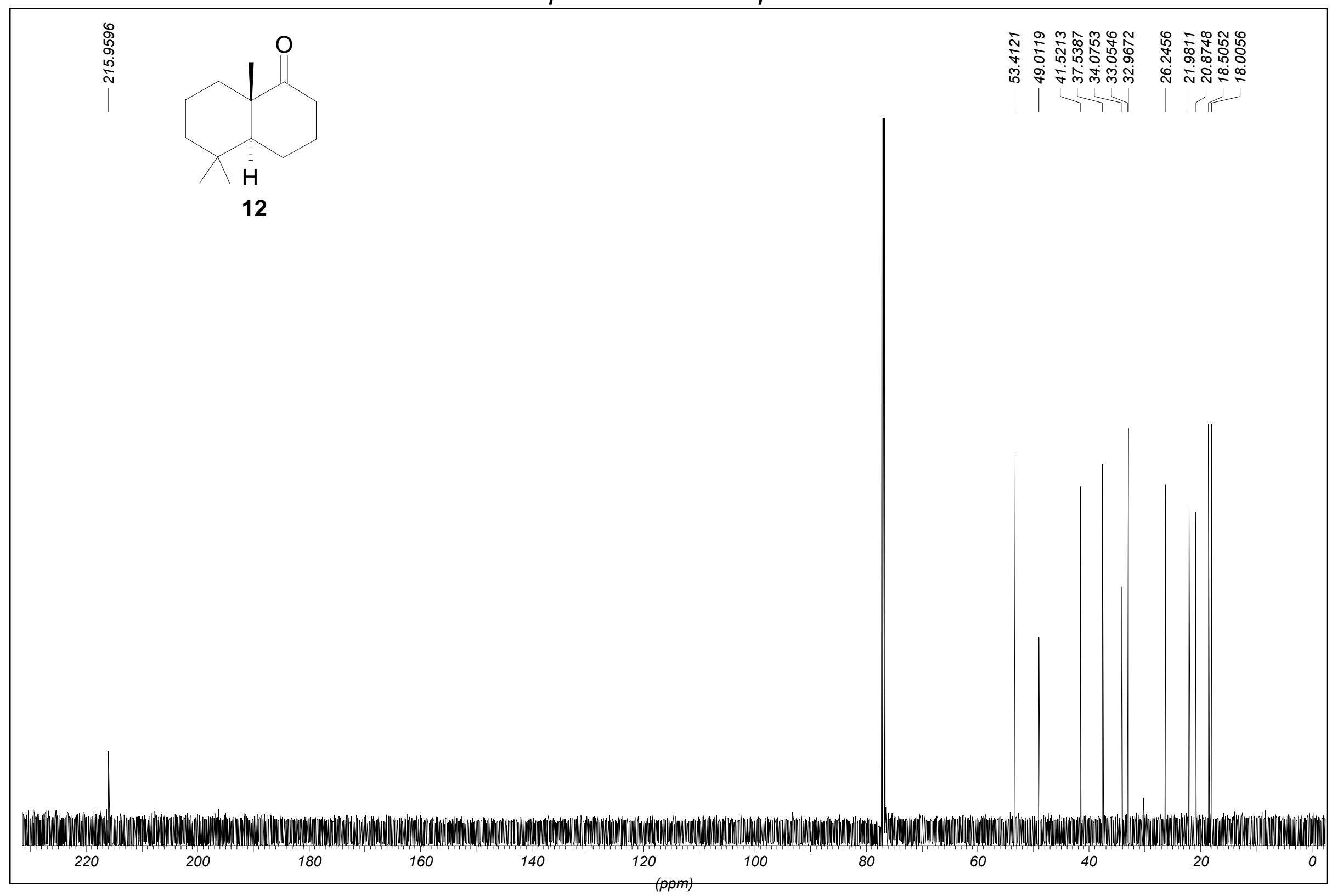


${ }^{1} \mathrm{H}$ NMR spectrum of compound 2
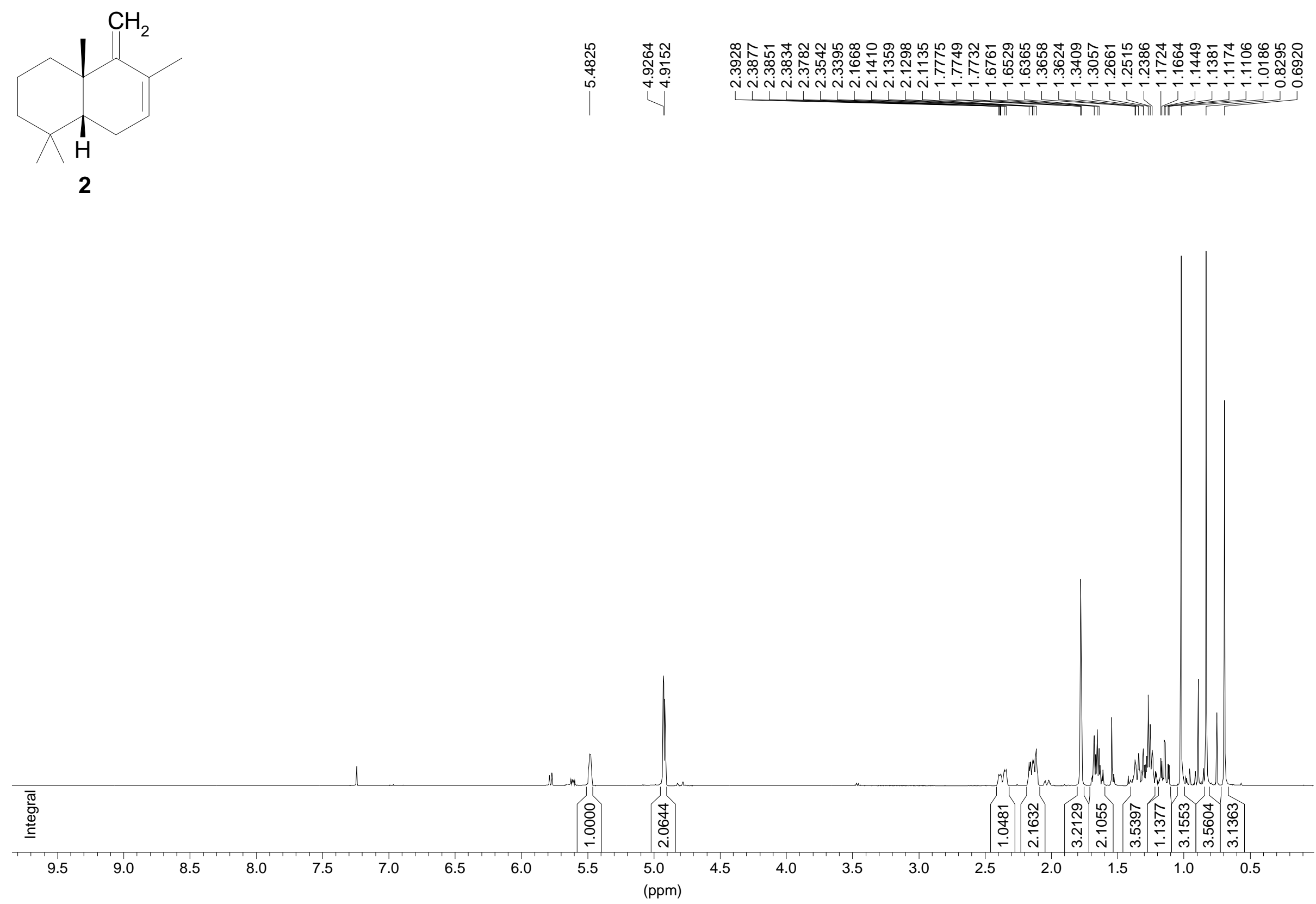


\section{${ }^{13} \mathrm{C}$ NMR and DEPT $\left(135^{\circ}\right)$ spectra of compound 2}

(+trace impurity)
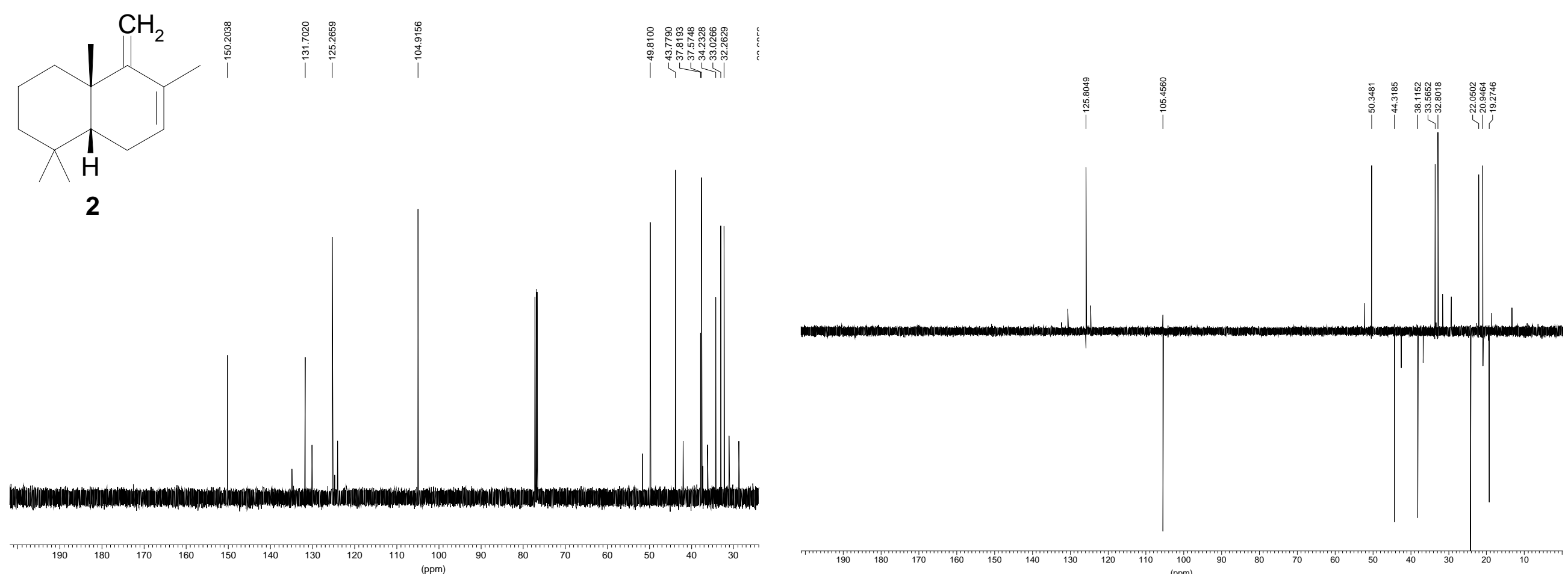
HMQC specrtum of compound 2

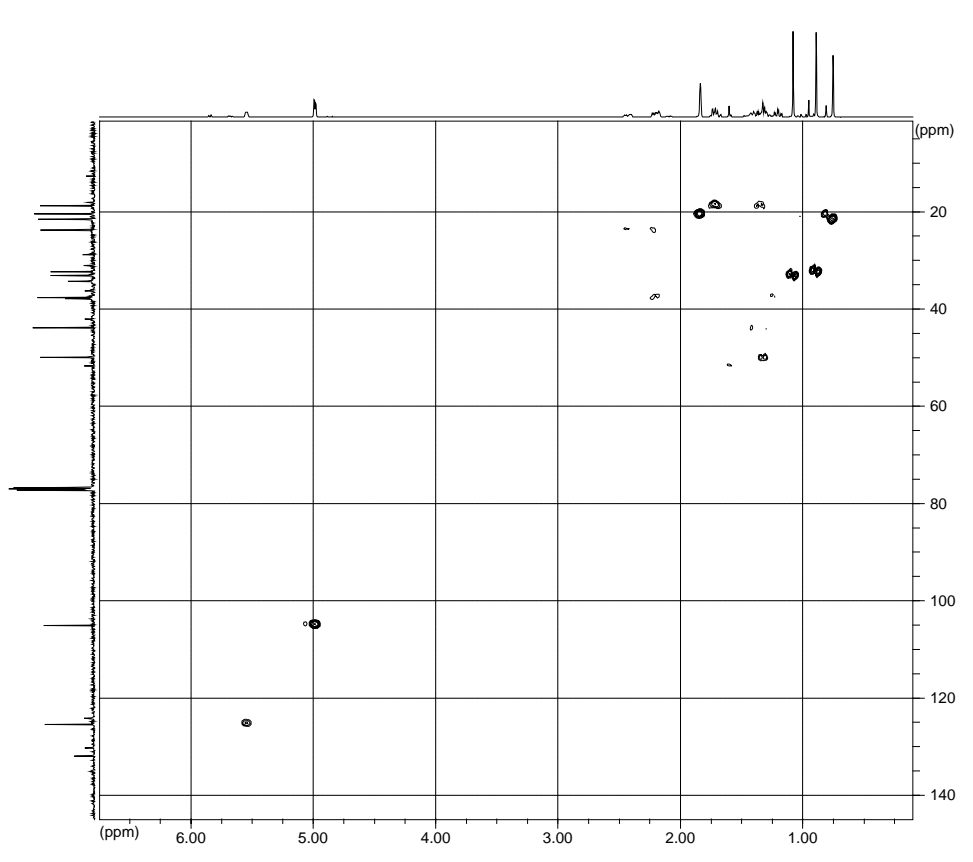

$\mathrm{CH}_{2}$

1

2 
NOESY spectrum of cis decalin system $\mathbf{9}$

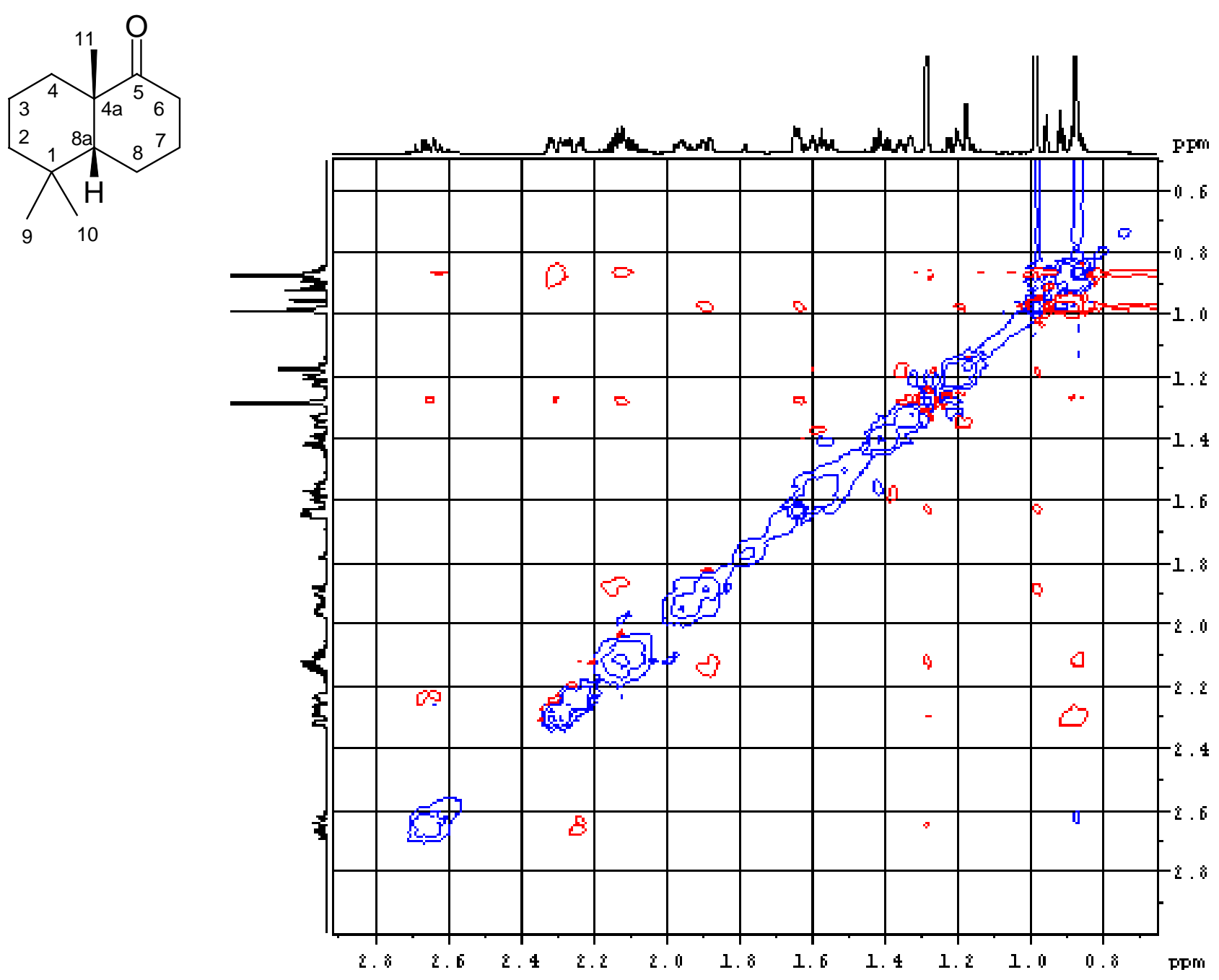


Mass spectra of isomeric compounds $\mathbf{9}$ and $\mathbf{1 2}$
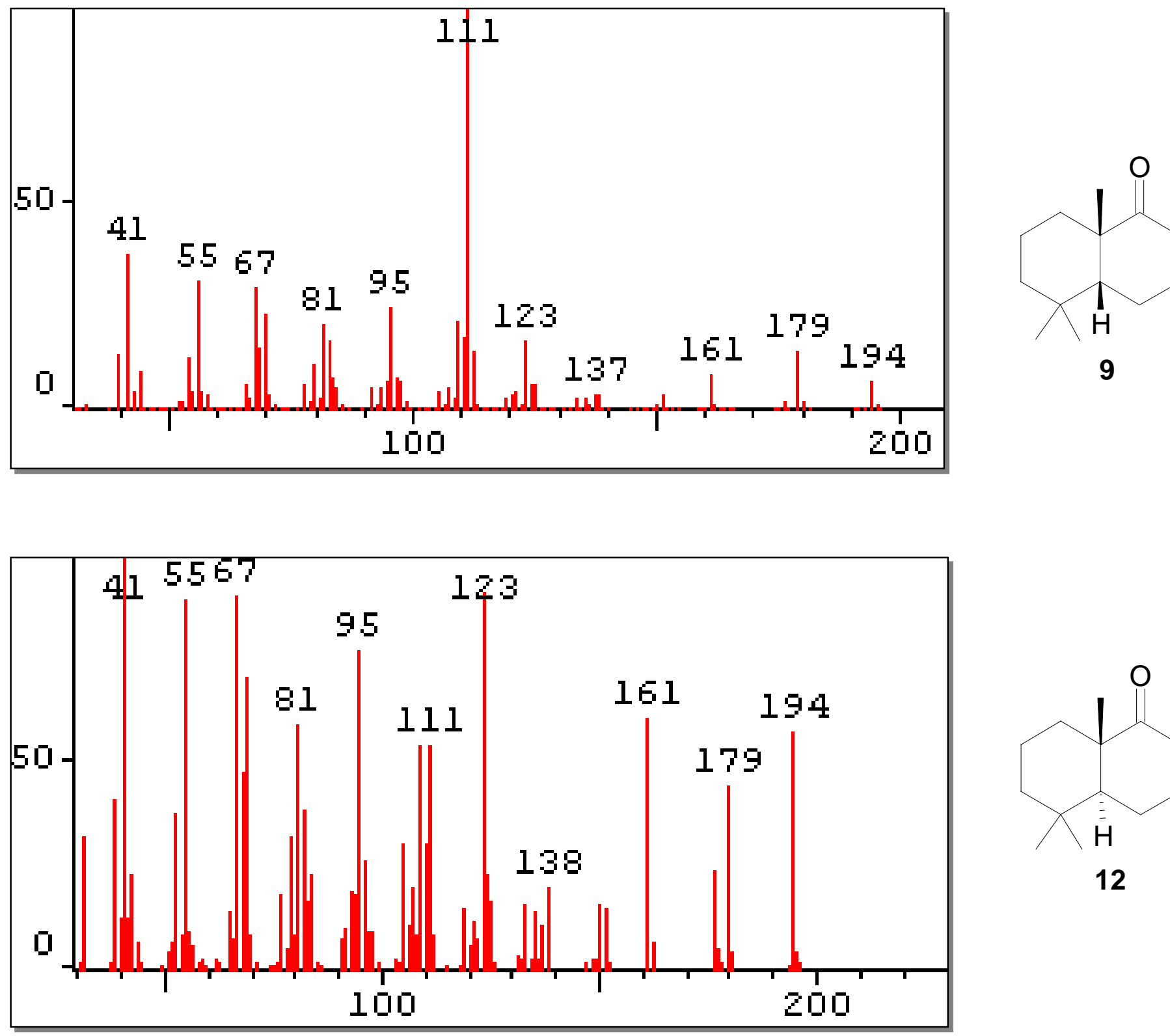
Mass spectrum of compound 2

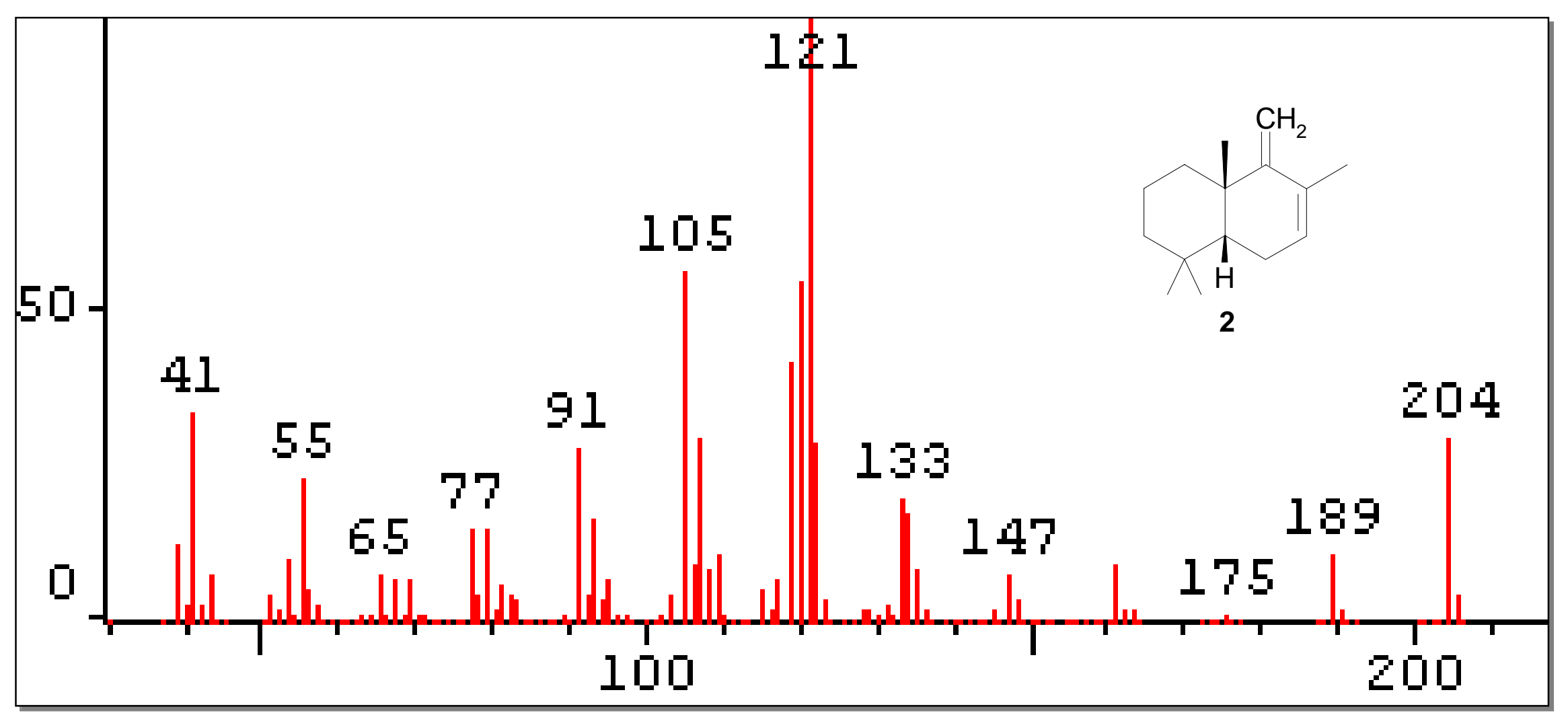




\section{COSY Spectum of Natural Product 3}
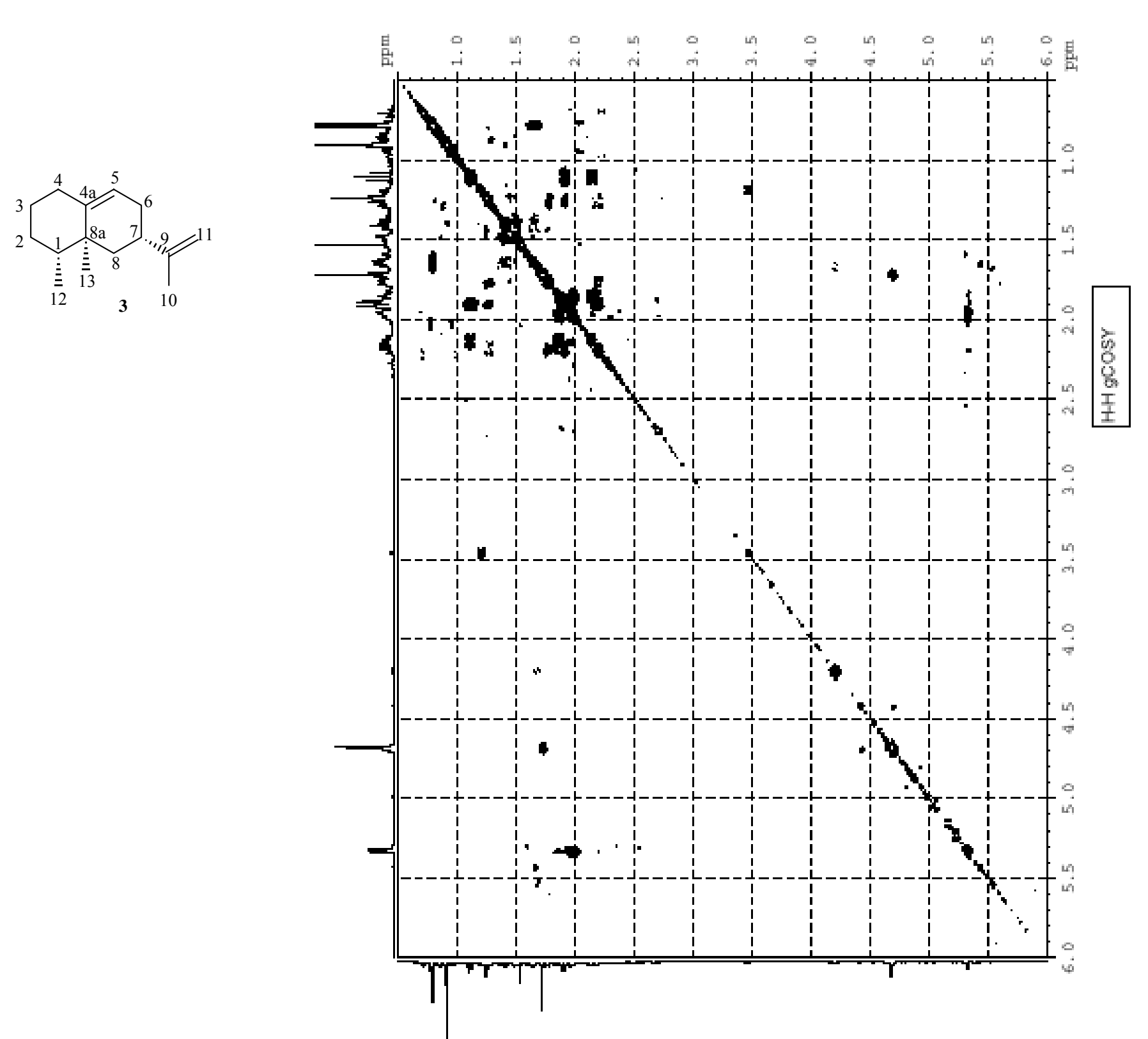


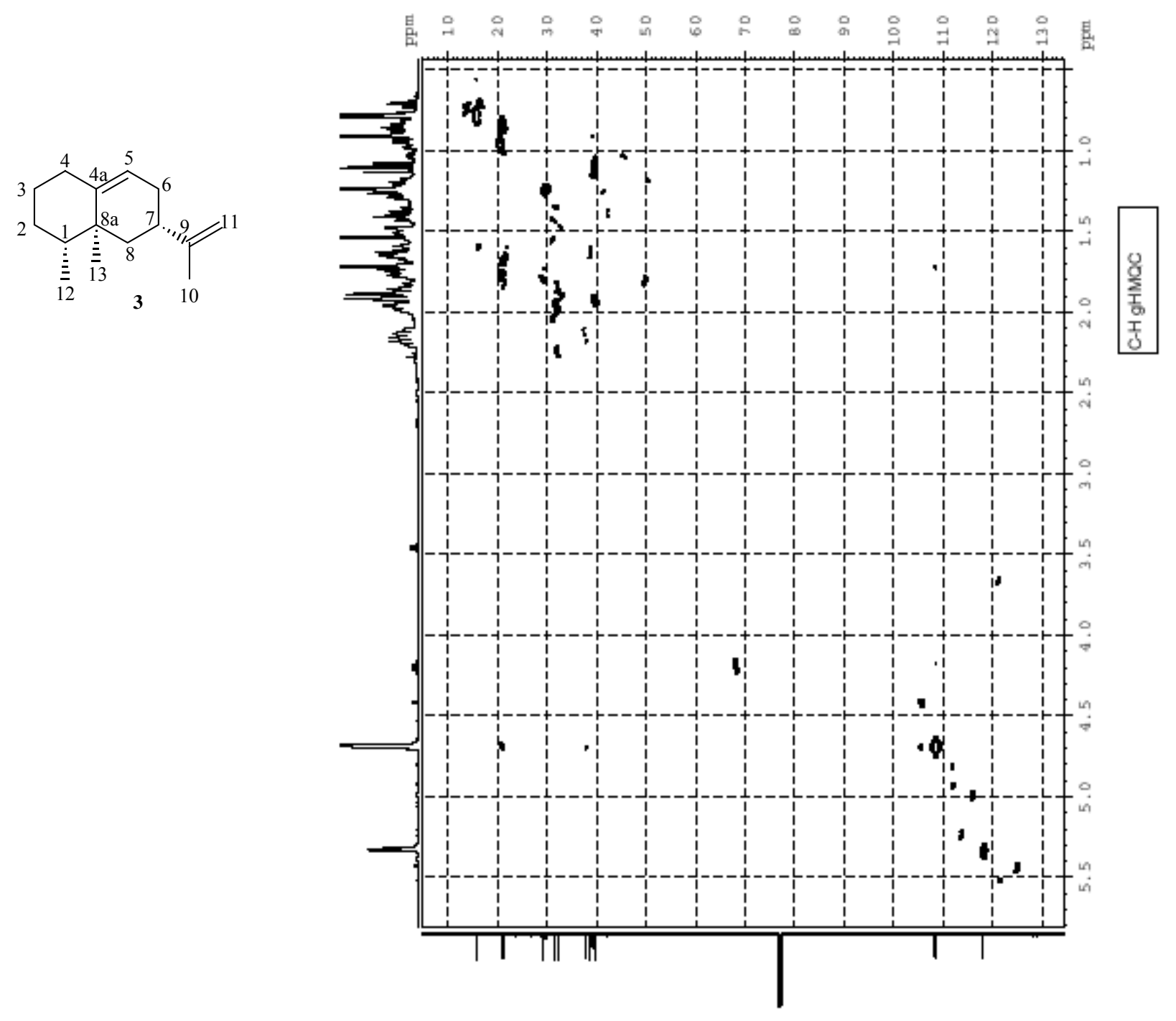

HMQC Spectrum of Natural Product 3. 
HMBC (long-range C-H) Spectrum of Natural Product 3
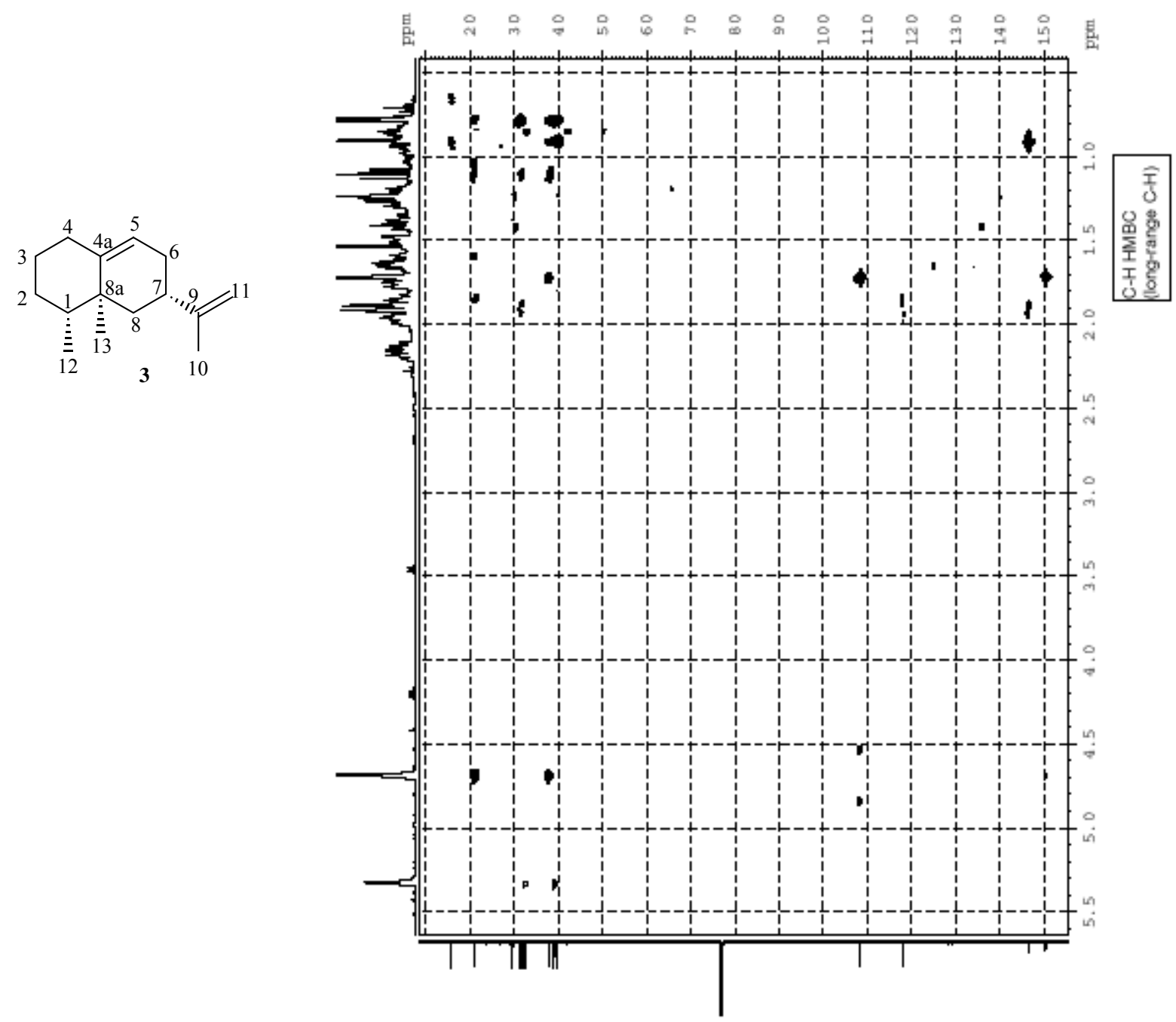


\section{${ }^{1}$ H NMR Spectrum of Natural Product 3}
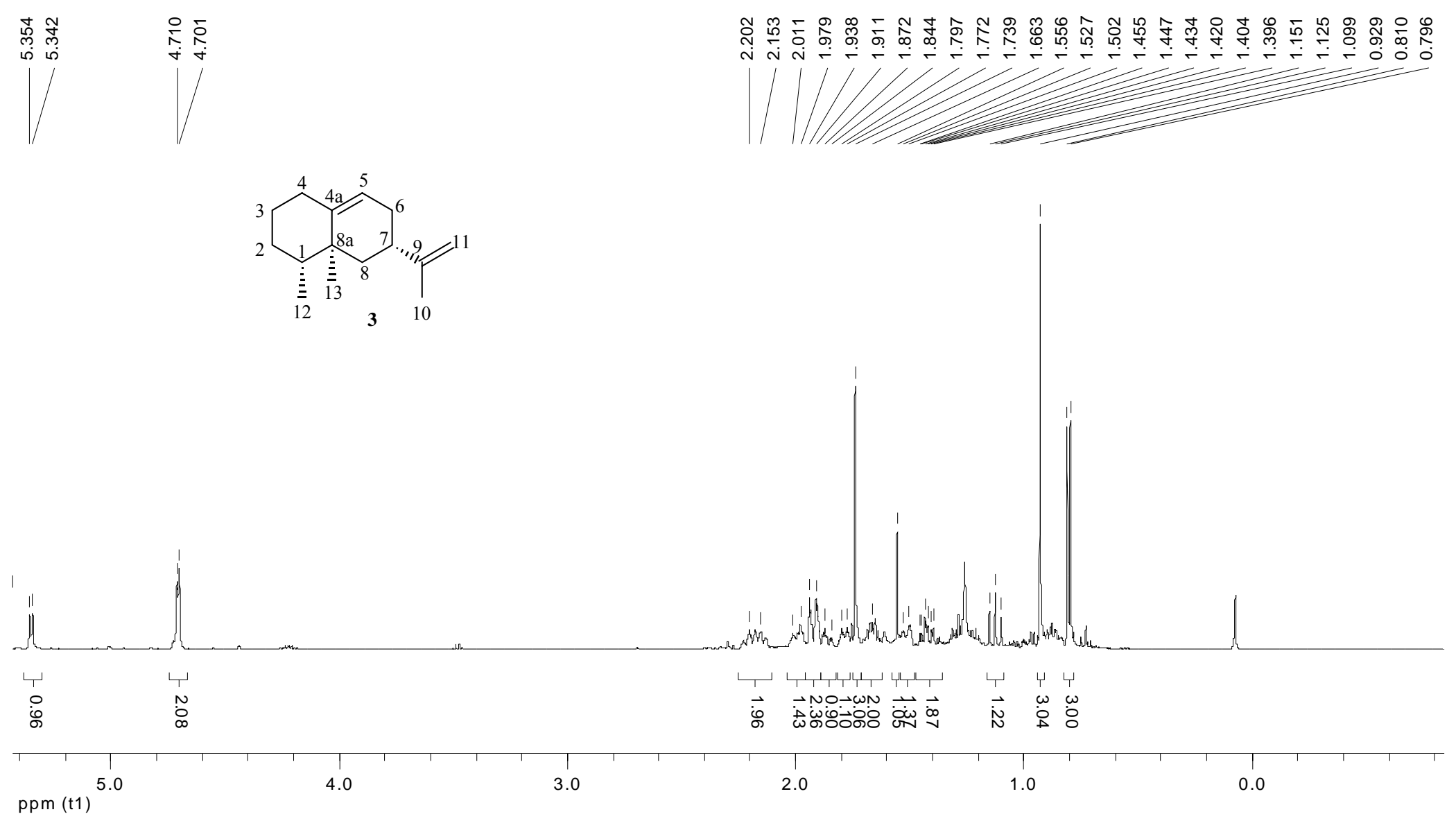


\section{${ }^{13} \mathrm{C}$ NMR Spectrum of Natural Product 3}
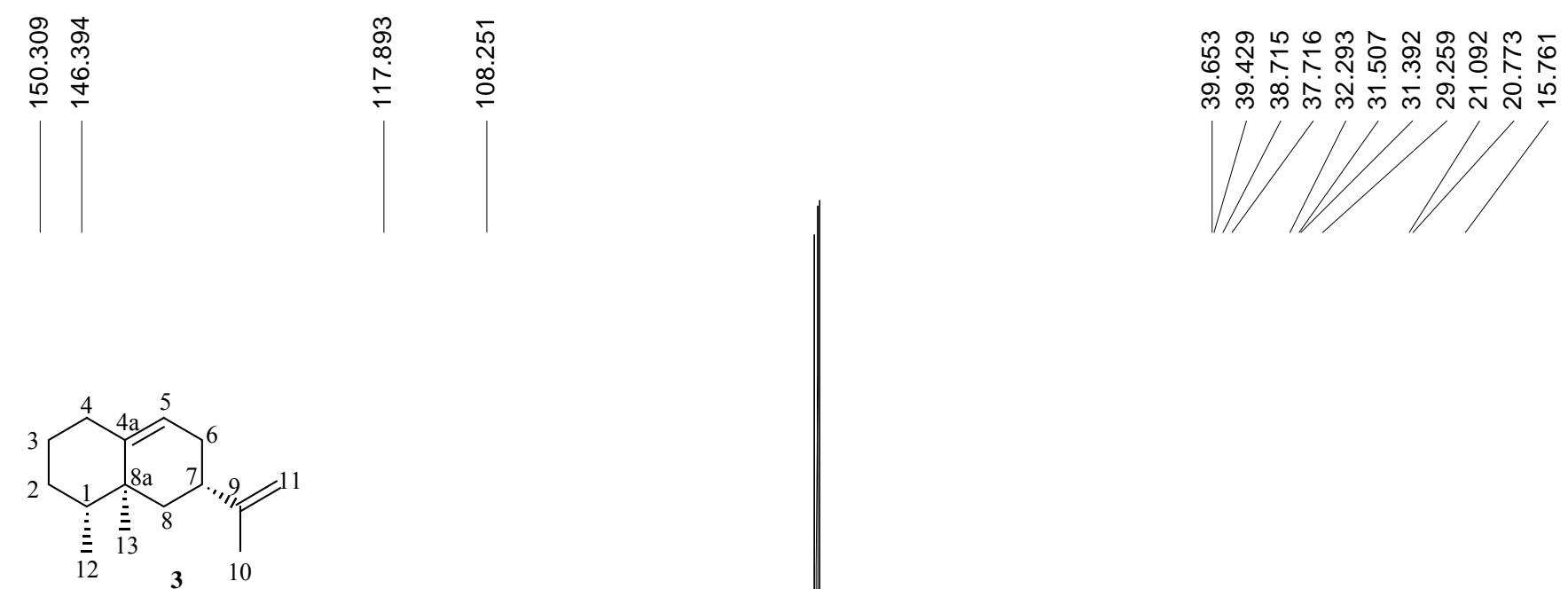

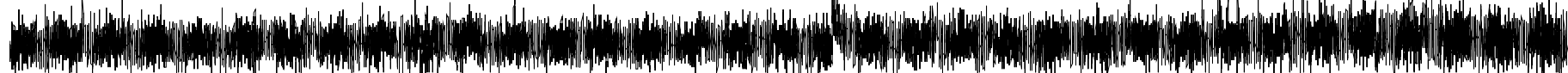




\section{DEPT $\left(135^{\circ}\right)$ Spectrum of Natural Product 3}
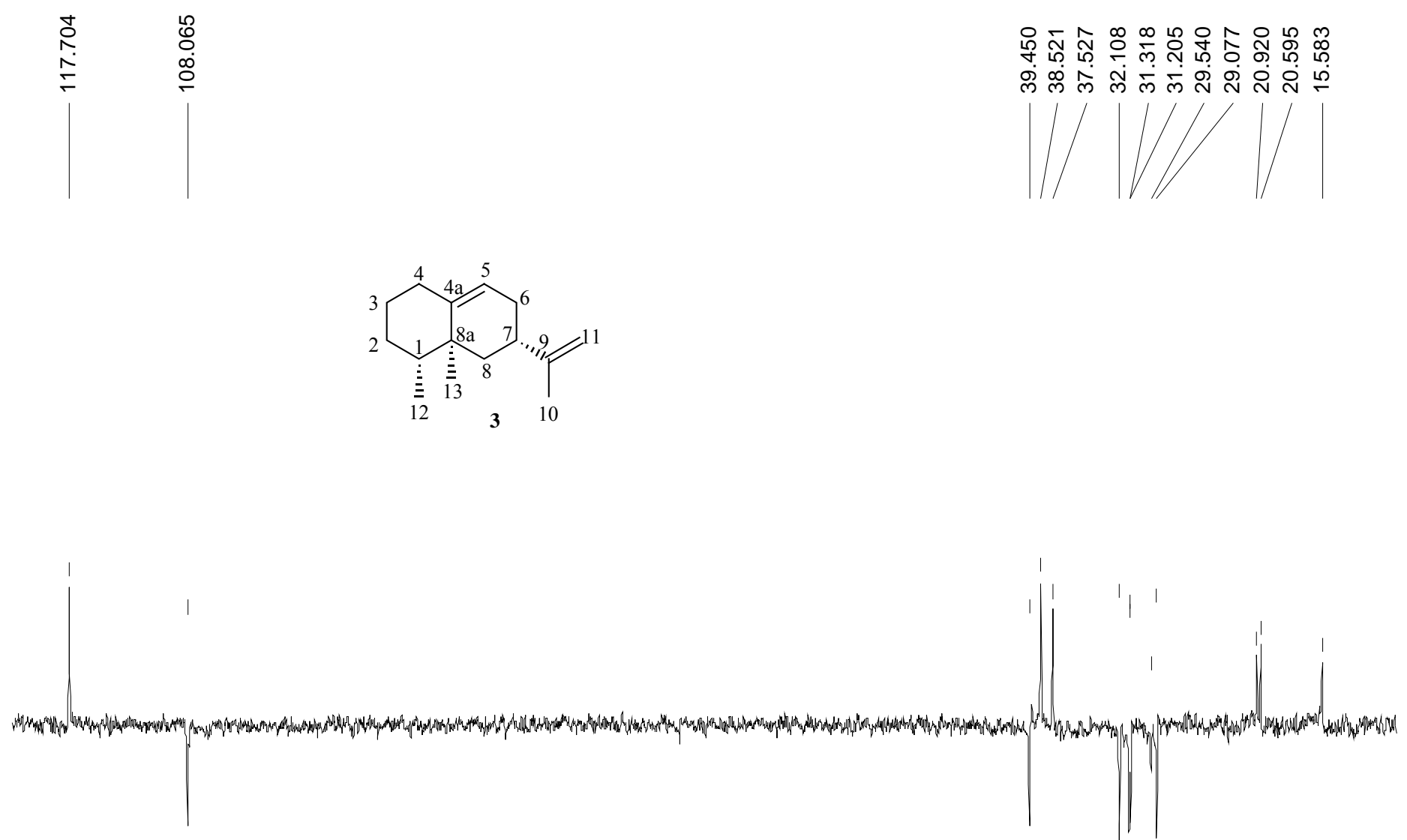
Mass Spectrum of Natural Product 3.

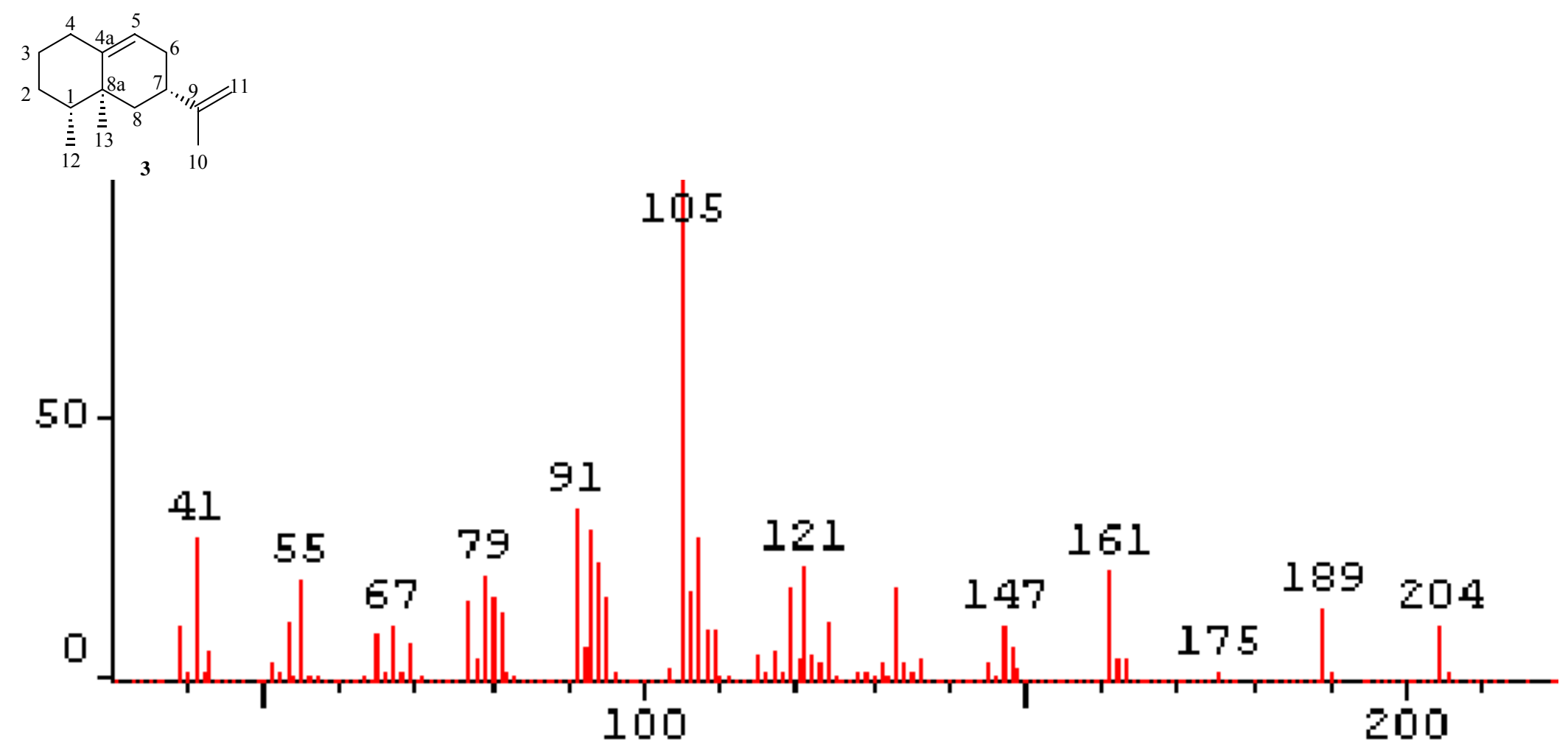

